\title{
Control of SCIG Based Constant Voltage Generation Scheme for Distributed Power Supply
}

\author{
Rupa Mishra and Tapas Kumar Saha \\ Department of Electrical Engineering, National Institute of Technology Durgapur, \\ Durgapur 713209, India
}

\begin{abstract}
This paper addresses the supply of power to the stand-alone load at constant voltage and constant frequency (CVCF), from a variable source distributed generation system. The inherent problem of having a fixed output from a variable input is prominent in all of the distributed generation systems, run by uncertain renewable sources like wind. This paper proposes a topology to maintain output load voltages and frequency during changes in both input torque and load perturbation. The control is designed for both the generator side and load side converters, connected as a back-to-back converter with one dc link capacitor. The voltage across dc link capacitor is maintained at a desired level by power flow control through the generator side voltage source converter (VSC). The proposed three-stage controller technique for the generator side converter is analysed and tested in all operating conditions. The outer most dc link voltage error is passing through the controller is generating the speed reference of the speed controller. Then the inner loop current controller follows the speed controller. The load side VSC is controlled to produce a constant voltage at the output of the load side filter. The stand-alone system has successfully been tested in the simulation environment. It is found to be capable of maintaining input power level to the demand, even with 50\% increment in load and 50\% increment in input torque. These dynamic responses of the variables are found to be satisfactory throughout the operation.
\end{abstract}

Keywords: Induction Machine (IM), Sinusoidal Pulse width modulation (SPWM), Squirrel cage induction generator (SCIG), Vector control (VC), Current control.

\section{Introduction}

The importance of renewable energy has been appreciated as alternative resources for power generation in the last few decades. Wind energy achieves a considerable fast growth amongst all the renewable energy resources [1]. The synchronous generator is not usually preferred for wind energy conversion systems (WECS), as it operates only at a constant speed while the wind speed is varying. Generally, the induction generator (IG) is chosen for the WECS because of the ability to operate at variable speed constant frequency (VSCF) operation [2]. Selection of the suitable generator for WECS is the challenging factor. The craggy construction and low continuation cost of the squirrel cage induction generators (SCIG) are preferred for $\mathrm{AC}$ drive appliances.

The requirement of reactive power by the directly grid connected SCIG leads to lower efficiency and earlier was supported by shunt capacitors [3].

The voltage build-up of SCIG requires residual magnetism, which seems to be unavailable with inaccessibility of its rotor circuit. Some methods like connection of shunt capacitor at the stator terminal [4] or a battery connected excitation capacitor is adjoined to the system. These conventional techniques are however increasing the complicacy of the topology, used for distributed power generation.

Interfacing distributed generating system to the grid is achieved through back-to-back converter, uncontrolled bridge rectifier and voltage source inverter, and matrix converter in [5]. The back-to-back converter is gaining attention amongst all the available converters. The vital reason for choosing back-to-back converter is the ability to extract maximal power from the

Received: August $14^{\text {th }}, 2017$. Accepted: September $20^{\text {th }}, 2018$

DOI: 10.15676/ijeei.2018.10.3.7 
prime mover [6]. The Double fed induction generator (DFIG) fed to stand-alone load [7] or grid [8] is also available with this converter. The DFIG is the suitable option for sites even with lower wind speed [9]. By integrating battery energy storage system (BESS) in DFIG, power supply remains invariant w.r.t. the wind speed. The SCIG driven stand-alone load through a VSC in [10], and the vector control (VC) technique is used for generating gate pulse. In [11], SCIG is feeding the load through a back-to-back converter. The generator side converter is controlled through a VC technique. The basic criterion of load side converter is to control the dc-link voltage [12]. The inner and outer loop bandwidths of the controllers are separated by a decade in general cases [13].

A novel control strategy of the DFIG fed to the grid-connected system has been analyzed in [14-16]. In [17], voltage and frequency control in the stator of stand-alone doubly operated induction generator (DOIG) has been discussed thoroughly. The design of a controller for DOIG based standalone VSCF application, by considering filter, has been designed in [17-18]. However the design of filter is clearly discussed in [19-21]. This design has been adopted for SCIG based stand-alone system in this work.

The proposed work developed a control strategy to supply fixed voltage and frequency to a stand-alone load from SCIG based distributed generation system. The control strategy is considering both load side voltage source converter (VSC) and the generator side VSC. Moreover, one filter is designed for load side VSC to compensate the voltage drop of the filter at different load level, in this work. None of the previous, work available in the literatures has shown the performance for both the load and generator side variations and supply of power with fixed voltage and frequency in SCIG driven stand-alone mode.

Specifically, the present work ensures: (i) Constant voltage constant frequency (CVCF) supply from the stand-alone system in all operating conditions. (ii) A novel three-stage control is proposed for the generator side VSC to supply regulated dc voltage at the input of the mentioned load side VSC. (iii) The dc link voltage controller is keeping the input power level same as the load demand by adjusting the speed of the generator in presence of variation in input torque also. The proposed system is handling both input torque and output load demand variations, while supplying quality power to one stand-alone load.

\section{Mathematical Modelling}

The scheme of the complete power and control topologies are presented in Figure 1. The control scheme includes SCIG driven by a constant prime mover, a back-to-back voltage source converter and the stand-alone load. The control strategy of the generator side VSC implemented is a vector control in rotor flux oriented reference frame. Simultaneously, the load side control algorithm is obtained in synchronously rotating load voltage oriented reference frame.

The dynamic model of SCIG is analyzed in rotor flux reference frame is as follows:

$$
\begin{aligned}
& V_{d s}^{r}=R_{s} i_{d s}^{r}+\frac{d \Psi_{d s}^{r}}{d t} \\
& V_{q s}^{r}=R_{s} i_{q s}^{r}+\frac{d \Psi_{q s}^{r}}{d t} \\
& V_{d r}^{r}=R_{r} i_{d r}^{r}+\frac{d \Psi_{d r}^{r}}{d t}=0 \\
& V_{q r}^{r}=R_{r} i_{q r}^{r}+\frac{d \Psi_{q r}^{r}}{d t}=0
\end{aligned}
$$

Where stator and rotor flux linkages in the $\mathrm{d}$ and $\mathrm{q}$ axis are expressed as:

$$
\begin{gathered}
\Psi_{d s}^{r}=L_{s} i_{d s}^{r}+L_{m} i_{d r}^{r} \\
\Psi_{q s}^{r}=L_{s} i_{q s}^{r}+L_{m} i_{q r}^{r}
\end{gathered}
$$




$$
\begin{aligned}
& \Psi_{d r}^{r}=L_{r} i_{d r}^{r}+L_{m} i_{d s}^{r} \\
& \Psi_{q r}^{r}=L_{r} i_{q r}^{r}+L_{m} i_{q s}^{r}
\end{aligned}
$$

The torque in this frame can be written as

$$
T_{e}=\frac{2}{3} \frac{p}{2} L_{m} i_{q s} \Psi_{r}
$$

Where, $R_{s}, R_{r}$ and $L_{s}, L_{r}$ are stator and rotor resistance, inductance; $L_{m}$ is magnetizing inductance. $i_{q s}, i_{d s}$ and $i_{q r}, i_{d r}$ Stator and rotor current in d-q axis; $p$ is pole pair.

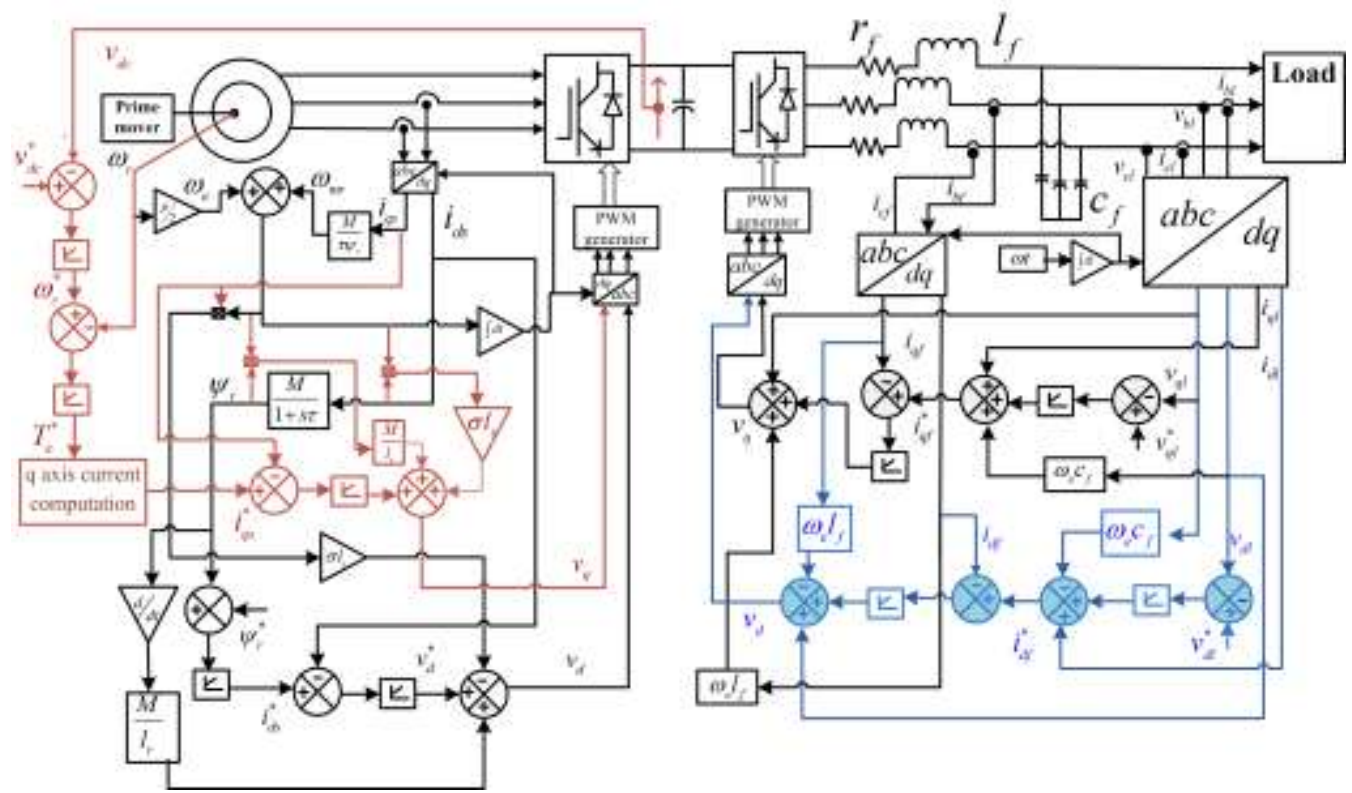

Figure 1. Proposed control strategy of SCIG fed to stand-alone load

\section{Control Strategies}

\section{A. Load side VSC}

This converter control strategy is to produce a constant voltage and frequency at the output of the load filter as shown in Figure 1. The control methodology is based upon projection of the filter current in the rotating reference frame. The d-axis load voltage of the synchronous frame is aligned with fixed voltage vector and q-axis voltage is kept zero in this scheme. The line-to-line load voltage is considered $230 \mathrm{~V}$ and d axis voltage is kept at $163 \mathrm{~V}$. The current and voltage state equations, for load side inverter including filter, are expressed as:

$$
\begin{aligned}
& \frac{d i_{a f}}{d t}=\left(\frac{\left(v_{a i}-\left(i_{a f} * r_{f}\right)-v_{a c}\right)}{l_{f}}\right) \\
& \frac{d i_{b f}}{d t}=\left(\frac{\left(v_{b i}-\left(i_{b f} * r_{f}\right)-v_{b c}\right)}{l_{f}}\right) \\
& \frac{d i_{c f}}{d t}=\left(\frac{\left(v_{c i}-\left(i_{c f} * r_{f}\right)-v_{c c}\right)}{l_{f}}\right)
\end{aligned}
$$




$$
\begin{aligned}
& \frac{d v_{a c}}{d t}=\left(\frac{\left(i_{a f}-i_{l a}\right)}{c_{f}}\right) \\
& \frac{d v_{b c}}{d t}=\left(\frac{\left(i_{b f}-i_{l b}\right)}{c_{f}}\right) \\
& \frac{d v_{c c}}{d t}=\left(\frac{\left(i_{c f}-i_{l c}\right)}{c_{f}}\right)
\end{aligned}
$$

The equivalent circuit diagram of the load VSC in synchronously rotating d-q reference frame is as shown in Figure 2(a),(b). The simplified controller diagram for the load controller is portrayed in Figure 3.

To facilitate controller design, the (10)-(15) are designed by using the d-q representation in the synchronous reference frame.

$$
\begin{aligned}
& v_{d i}=\left(i_{d f} r_{f}\right)+l_{f} \frac{d i_{d f}}{d t}+v_{d c}-\omega_{e} l_{f} i_{q f} \\
& v_{q i}=\left(i_{q f} r_{f}\right)+l_{f} \frac{d i_{q f}}{d t}+v_{q c}+\omega_{e} l_{f} i_{d f} \\
& i_{d f}=i_{d l}+c_{f} \frac{d v_{d c}}{d t}-\omega_{e} c_{f} v_{q c} \\
& i_{q f}=i_{q l}+c_{f} \frac{d v_{q c}}{d t}+\omega_{e} c_{f} v_{d c}
\end{aligned}
$$

Where $i_{a f}, i_{b f}, i_{c f}$ and $v_{a c}, v_{b c}, v_{c c}$ are Filter current and voltage across capacitor. $l_{f}, c_{f}$ Denotes filter inductance and capacitance.

\section{B. Three-stage control technique of Generator-side VSC}

Another interesting objective of this paper is to keep the dc-link voltage constant, regardless of the amount of the load demand and input power variation. The $\mathrm{VC}$ is developed with reference frame aligned with the rotor flux, which enable controlling active and reactive power independently.

The $\mathrm{d} \mathrm{q}$ axis voltages can be written as:

$$
\begin{aligned}
& V_{d s}^{r}=\left(R_{s} i_{d s}^{r}+\sigma L_{s} \frac{d i_{d s}^{r}}{d t}\right)+\frac{L_{m}}{L_{r}} \frac{d \Psi_{r}}{d t}-\sigma L_{s} i_{q s}^{r}\left(\omega_{m r}+\omega_{e}\right) \\
& V_{q s}^{r}=\left(R_{s} i_{q s}^{r}+\sigma L_{s} \frac{d i_{q s}^{r}}{d t}\right)+\frac{L_{m}}{L_{r}} \Psi_{r}\left(\omega_{m r}+\omega_{e}\right)+\sigma L_{s} i_{d s}^{r}\left(\omega_{m r}+\omega_{e}\right)
\end{aligned}
$$

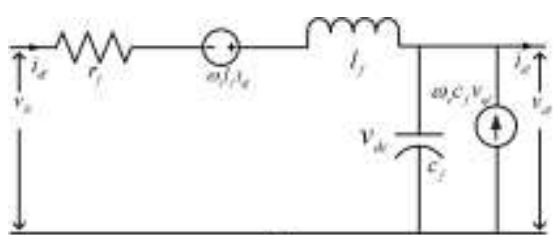

(a)

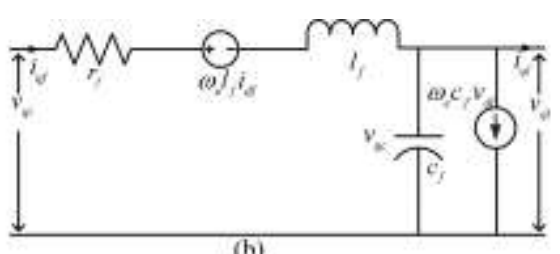

(b)

Figure 2. Equivalent circuit of the inverter (a) d-axis, (b) q-axis 


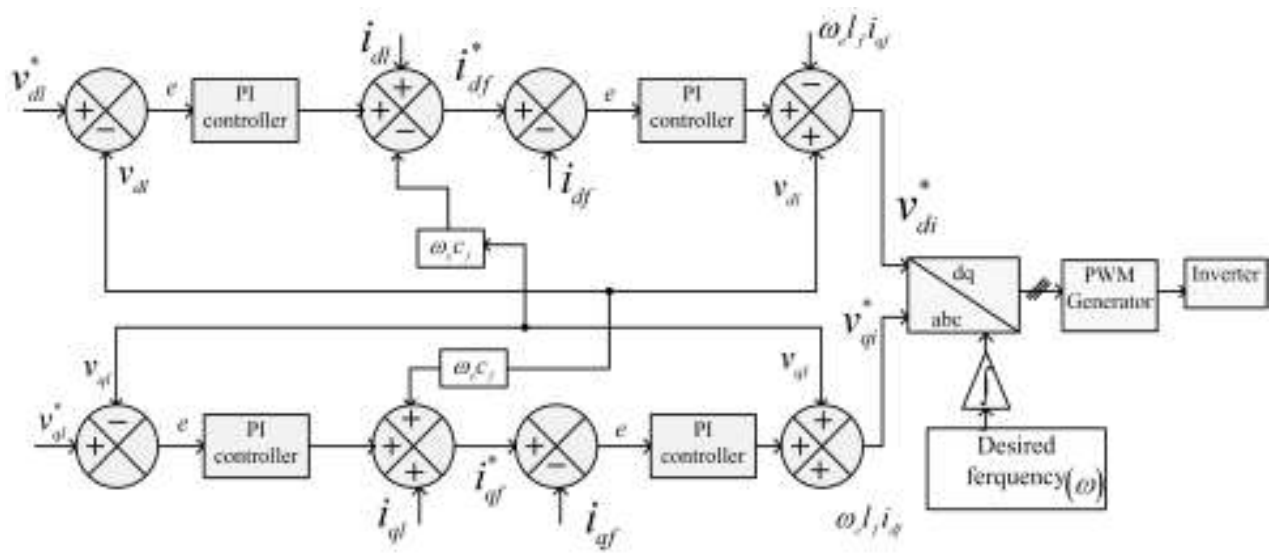

Figure 3. Proposed control methodology of load side converter

The error of dc link voltage is passing through PI controller generate speed command as shown in (22).

$$
\omega_{r}^{*}=\left\{\left(k_{p d}+\frac{k_{i d}}{s}\right)\left(V_{d c}^{*}-V_{d c}\right)\right\}
$$

The reference torque can be generated as:

$$
T_{e}^{*}=\left\{\left(k_{p 1}+\frac{k_{i 1}}{s}\right)\left(\omega_{r}^{*}-\omega_{r}\right)\right\}
$$

Where, $V_{d c}, V_{d c}^{*}$ Actual and Reference dc-link voltage; $\omega_{r}, \omega_{r}^{*}$ are actual and reference speed of synchronous reference frame.

When the speed error passed through speed controller, reference torque is generated in (23) and from this, by the use of (9) the reference value of q-axis component of stator current is calculated. The flux error is passing through the PI controller generate the d-axis component of the machine current as given in (24). At the final stage, the error of the d-axis component of the machine current passes through the PI controller to generate the $\mathrm{d}$-axis voltage as portrayed in (20).

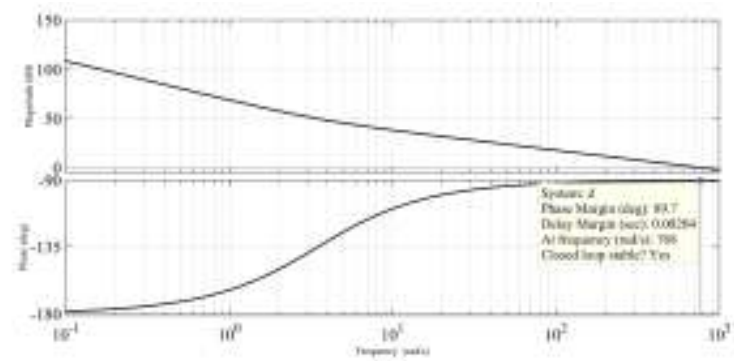

(a)

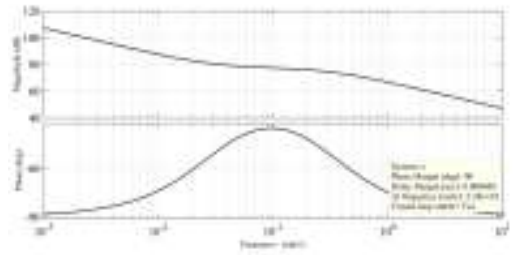

(b)

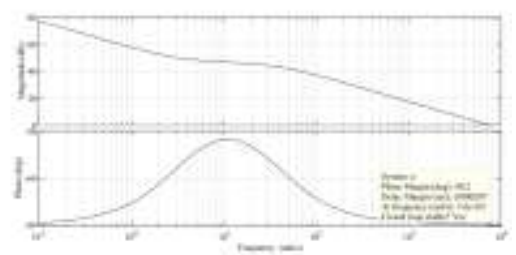

(c)

Figure 4. Frequency response of (a) dc link voltage controller (b) speed controller and (c) current controller 


$$
i_{d s}^{*}=\left\{\left(k_{p 1}+\frac{k_{i 1}}{s}\right)\left(\Psi_{r}^{*}-\Psi_{r}\right)\right\}
$$

The current controllers are designed to cause the generation of $\mathrm{d}$ and $\mathrm{q}$ axis voltages using the (20) and (21). The bandwidths of current controllers $\left(k_{p}, k_{i}\right)$ are taken as three times of the speed controller $\left(k_{p 1}, k_{i 1}\right)$. Again, speed controller bandwidth is three times of the voltage controller. From the Bode plot shown in Figure 4(a), it is clear that bandwidth of the voltage controller is $767.8 \mathrm{rad} / \mathrm{s}$. In the case of speed and current controller as shown in Figure 4(b), Figure 4(c), the system is inherently stable as the gain margin is infinite. Phase margin for both the system is set at $90^{\circ}$ at the frequency of $2280 \mathrm{rad} / \mathrm{s}$ in case of speed control and $7620 \mathrm{rad} / \mathrm{s}$ for current control.

The 2-phase to three phase conversion has been achieved with the VC approach. The pulse width signal is generated after comparing this modulating signal with a carrier wave.

\section{System Description}

The system is tested under the following condition:

Machine specification: $1 \mathrm{hp}, 750 \mathrm{rpm}, 220 \mathrm{~V}, 7 \mathrm{~A}, 50 \mathrm{~Hz}$.

DC link voltage is $400 \mathrm{~V}$.

Filter parameter:

Inductor with $8 \mathrm{mH}$, resistance is $0.1 \Omega$ and capacitance $8.0938 \mu \mathrm{F}$.

\section{Results and Discussion}

The control technique and its implementation for the SCIG described in the previous section is simulated in MATLAB/SIMULINK environment. The topology is validated with load impedance perturbation and step change in input torque.

\section{A. Load Perturbation}

The system is starting with $40 \%$ of rated load and then subjected to an increment of $100 \%$ in the active power, in a step. During step change in stand-alone load, the rms value of the output current increases from 0.65A to 1.25A, as shown in Figure 5.

The d-axis and q-axis component of the load voltages are portrayed in Figure 6(a) and 6(b). The $\mathrm{d}$ axis component of the load voltage is maintaining at the desired level of $163 \mathrm{~V}$ during the study. The voltage controllers (the block diagram as shown in Figure 3) settle the transient variation in these voltages, during the load increment and decrement, successfully within $0.8 \mathrm{~s}$. The q-axis component of the load voltage is kept at the level zero throughout operation successfully. With fixed $\mathrm{d}$ axis and zero q-axis load voltage, the active power becomes $(3 / 2) v_{d} i_{d}$, and the reactive power generation becomes-(3/2) $v_{d} i_{q}$. The $d$-axis component of the load current is found to be increasing during a step change in load, as shown in Figure 6(c). The reactive power demand also increases during this step change. Therefore, the q-axis component of the load current is following the nature as portrayed in Figure 6(d). The lagging reactive demand had met by an increment in this negative current. 


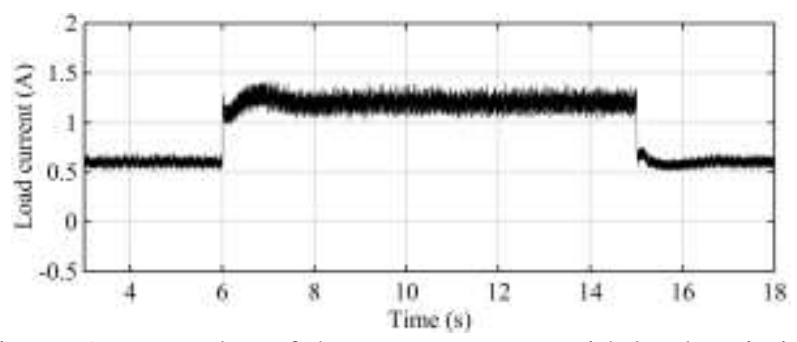

Figure 5. Rms value of the output current with load variation

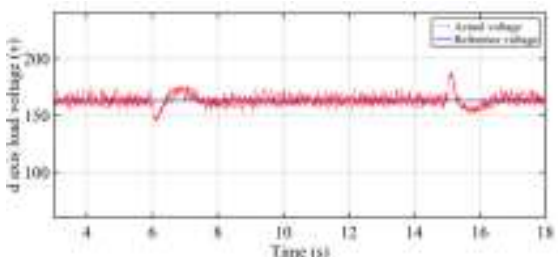

(a)

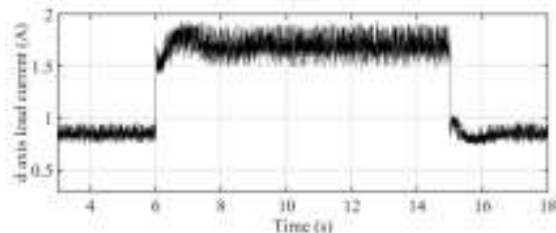

(c)

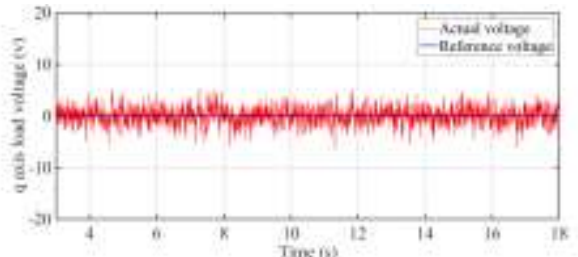

(b)

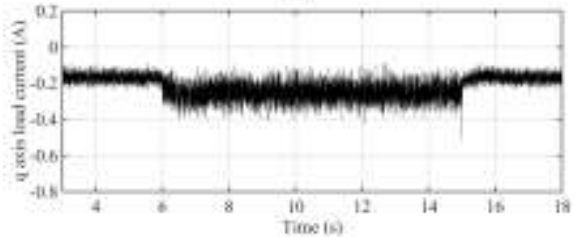

(d)

Figure 6. The transient behavior of variables during step change in load demand: (a) d-axis load voltage, (b) q-axis load voltage, (c) d-axis component of load current, and (d) q-axis component of load current

The total harmonic distortion (THD) of the output voltage and current is keeping within a small limit by the use of filter. The THD of the load voltage found to be $2.79 \%$, at steady state, as displayed in Figure 7(b) and the THD of the load current, at the same time, is $1.88 \%$, as shown in Figure 7(d).

The load variation is supported by a change in power flow from the machine side converter, which is controlled by the three-stage controller, developed in section $3 \mathrm{~B}$. The transient behavior of the dc-link voltage is portraying in Figure 8(a). The dc link voltage is maintaining

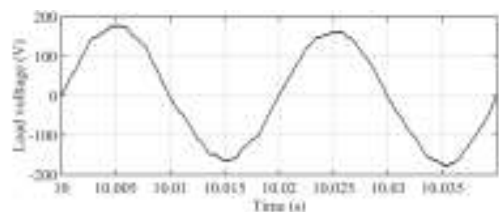

(a)

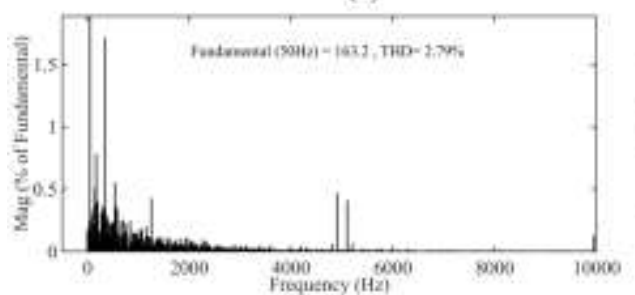

(b)

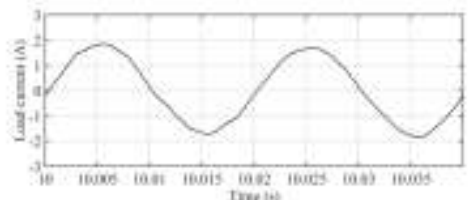

(c)

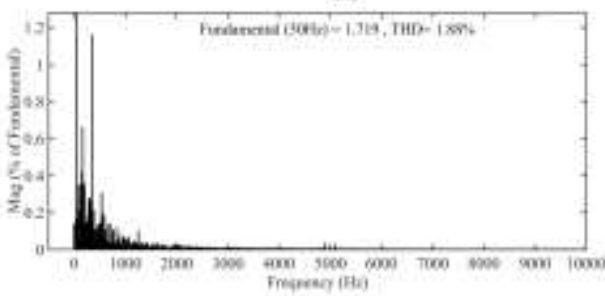

(d)

Figure 7. The quality of: (a) Load voltage (b) FFT of load voltage (c) Load current (d) FFT of load current, with higher load. 


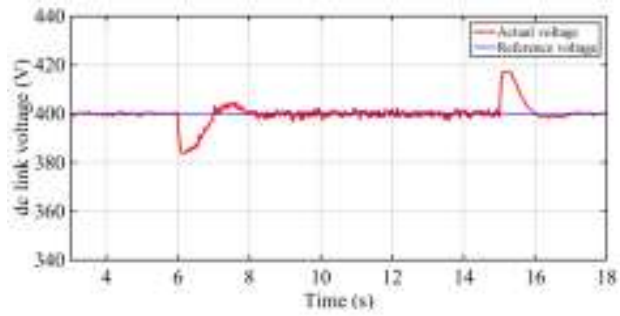

(a)

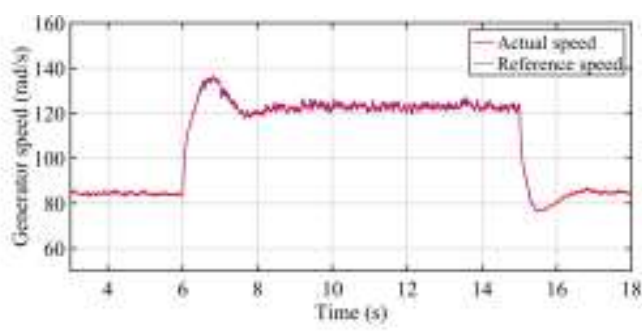

(b)

Figure 8 . The transient behavior of variables during step change in load demand: (a) dc link voltage, (b) generator speed

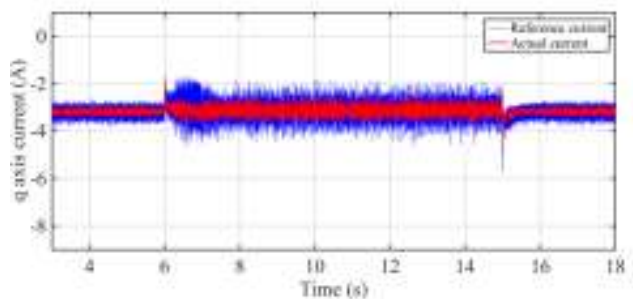

(a)

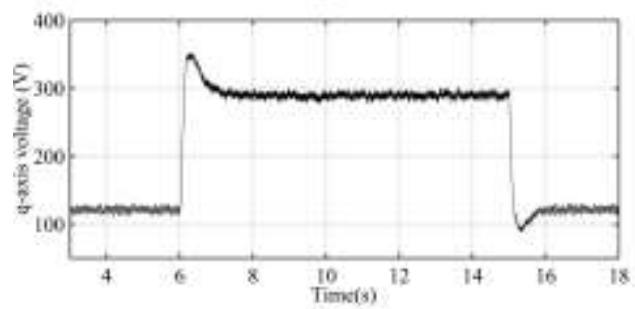

(c)

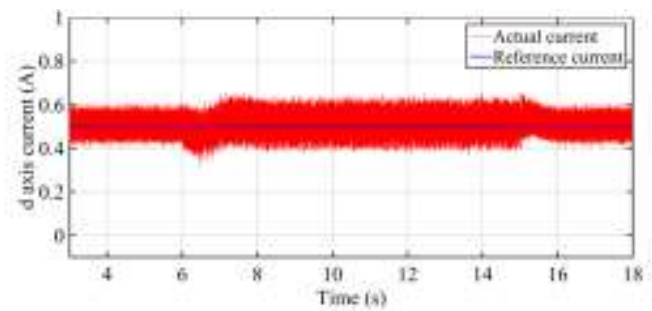

(b)

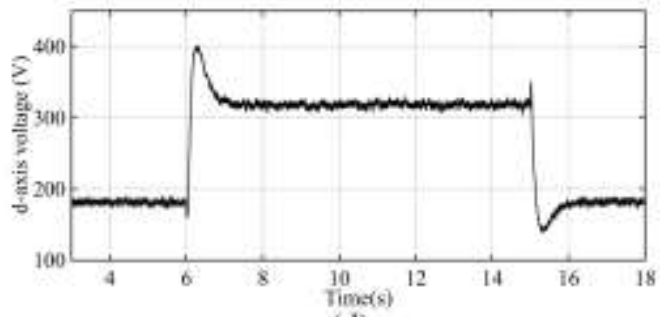

(d)

Figure 9. The transient behavior of variables during step change in load demand: (a) q-axis component of machine current, and (b) d-axis component of machine current, (c) q-axis component of machine voltage, and (d) d-axis component of machine voltage

at the desired $400 \mathrm{~V}$ level, with less than $4.5 \%$ transient variation during both increment and decrement in the load at $6 \mathrm{~s}$ and $15 \mathrm{~s}$ respectively. The speed command of the generator is increasing through the dc link voltage controller during the load demand increment. The input torque during this transient is considered as constant, and so is able to generate more power to meet the load demand with increased speed. The actual and reference speed of the generator, during this load variation, are as shown in Figure 8(b). The actual speed is closely following the reference one, in this figure. The speed controller works successfully during the decrement of the load also. The q-axis component of the machine current remains at the constant level of 3.3 A, with transient changes during the load variation. The transient behavior of this current is displaying in Figure 9(a).

The direct axis component of machine current remains invariant during the load transient. The nature of this current is portrayed in Figure 9(b). However, the $d$ and $q$ axis components of machine voltage are changing to accommodate the increment in the load power demand, as portrayed in Figure 9(c) and Figure 9(d). The total power supplied by the machine side converter increases by $314 \mathrm{~W}$ due to the change in the considered load demand.

\section{B. Variation in Input torque}

Considering the load is constant, a step increment in the input torque is providing to the system to verify the operation of the control with variable input. The input torque is increasing 
by $50 \%$ at $15 \mathrm{~s}$ as presented in Figure 10. The changes on the stator side and load side variables, because of this input variation, are showing in Figure 11 and Figure 13.

The d-axis component of the load voltage is going through a small transient disturbance at $15 \mathrm{~s}$ and settled back to the reference level, $163 \mathrm{~V}$, as shown in Figure 11(a). However, the q-axis component of the load voltage is maintaining constant at zero through the controller, as shown in Figure 11(b).

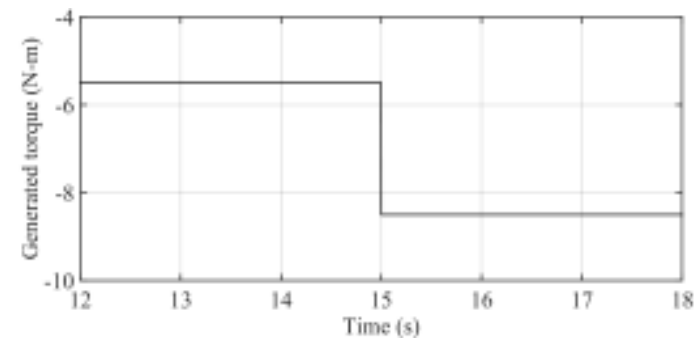

Figure 10. Input torque variation

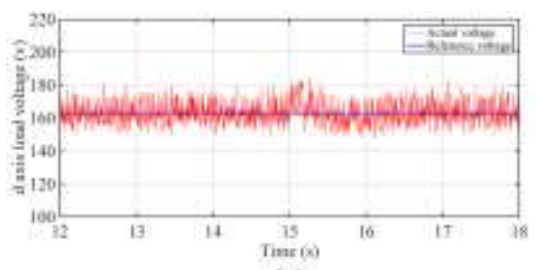

(a)

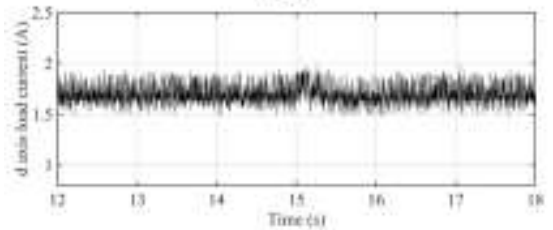

(c)

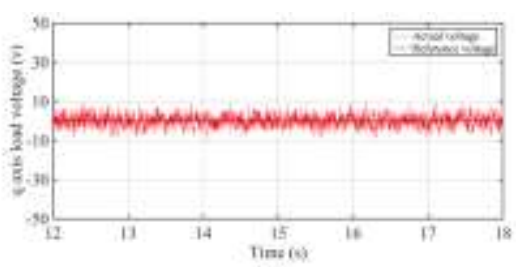

(b)

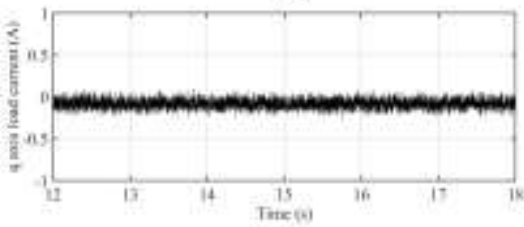

(d)

Figure 11. The transient behavior of variables during step change in input torque: (a) d-axis load voltage, (b) q-axis load voltage, (c) d-axis component of load current, and (d) q-axis component of load current

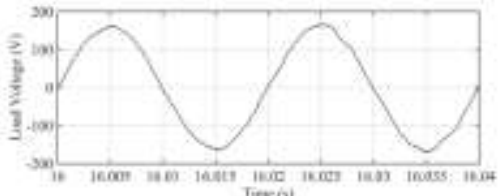

(a)

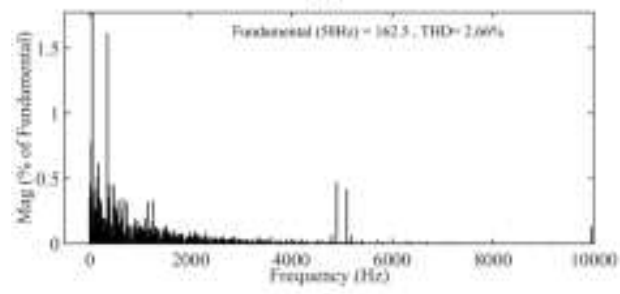

(c)

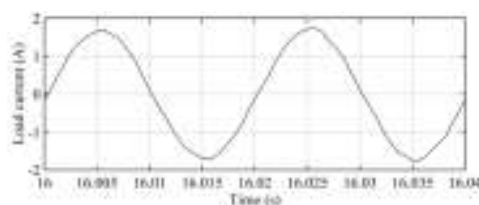

(b)

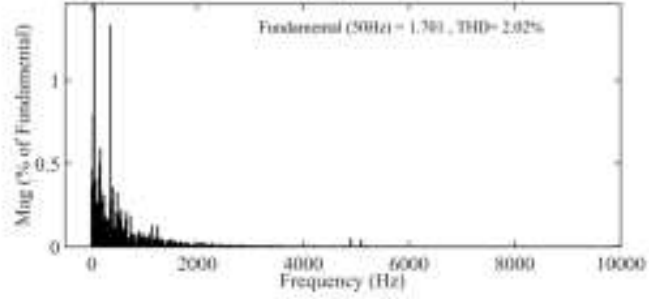

(d)

Figure 12. Quality of: (a) Load voltage (b) Load current (c) FFT of load voltage (d)FFT of load current, with higher input torque 
The constant voltage at the output of filter allows the load current to be same, even with the change in the input torque. The d-axis and q-axis components of the load currents are so constant throughout the operation and shown in Figure 11(c) and 11(d).

The total harmonic distortion (THD) of the output voltage and current is keeping within a small limit by use of the filter in this case also. The THD of the load voltage is finding to be $2.66 \%$ at steady state, as shown in Figure 12(c) and the THD of the load current, at the same time, is of $2.02 \%$, as shown in Figure 12(d).

Both Figure 7 and Figure 12 are portraying the efficacy of the filter output control for this stand-alone system. The developed voltage control is improving the power quality even with $100 \%$ variation in load and $50 \%$ variation in input torque.

The dc link voltage is successfully controlling to maintain at $400 \mathrm{~V}$ level, with $2 \%$ variation in transient condition as shown in Figure 13(a). The operating speed is reducing with higher input torque to supply constant load power. The speed controller is successfully following the reference command as shown in Figure 13(b).

It is also observing from Figure 14 (a), that the q-axis component of the machine current, increases to $-4.5 \mathrm{~A}$ from $-3.2 \mathrm{~A}$ in the result of the increment in increased input torque at $15 \mathrm{~s}$. However, the $\mathrm{d}$ and $\mathrm{q}$ axis components of machine voltage are changing to meet the same load power demand, as portrayed in Figure 14(c), Figure 14 (d).

The total power supplied by the machine side converter is keeping same for the change in the input torque. The current controller is successfully controlling the actual current to follow the reference, throughout the operation. The d-axis component of machine current is constant, as portrayed in Figure 14 (b). As a result, there is no such variation in d-axis voltage, as shown in Figure 14(d).

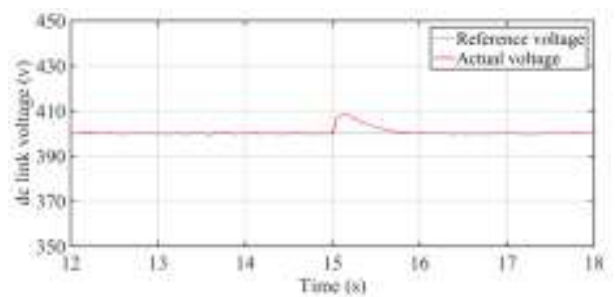

(a)

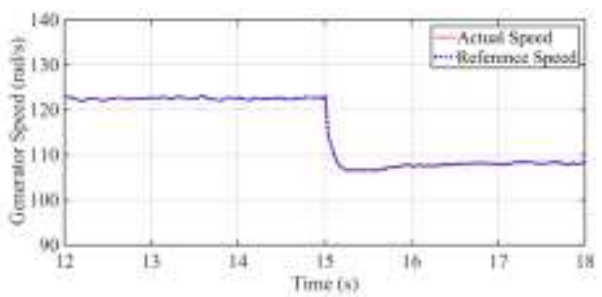

(b)

Figure 13. The transient behavior of variables during step change in input power: (a) dc link voltage, (b) generator speed

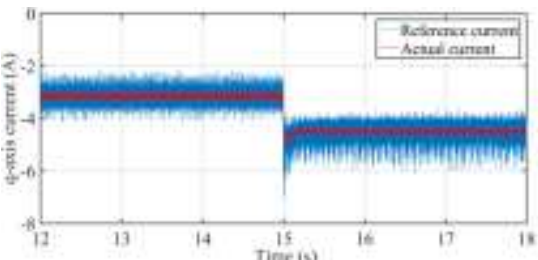

(a)

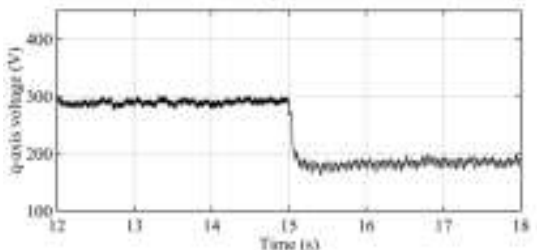

(c)

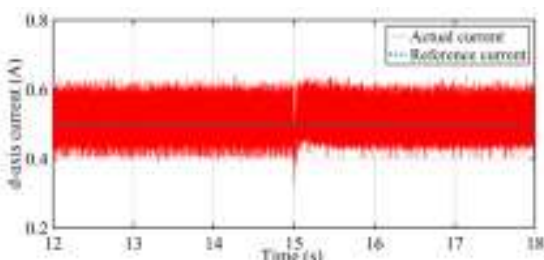

(b)

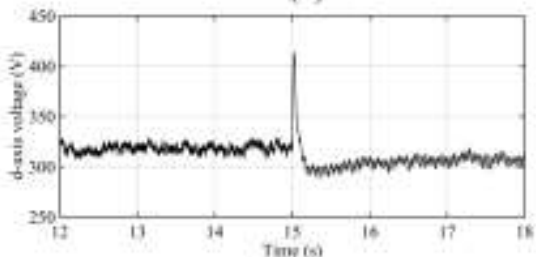

(d)

Figure 14. The transient behavior of variables during step change in input power: (a) q-axis component of machine current, and (b) d-axis component of machine current (c) q-axis component of machine voltage, and (d) d-axis component of machine voltage 


\section{Conclusion}

Two controllers are designed for generator side VSC and for load side VSC to achieve fixed voltage and frequency output with both input torque and load impedance variation, in this work. The three -stage controller is designed for the generator side VSC to maintain the dc link voltage constant throughout the operation. The load side VSC is controlling simultaneously to provide a constant voltage at the output. Moreover, one filter is incorporated to reduce the harmonics at the load end, and the already designed load side controller compensates the drop of the load voltage.

The control is implemented with both load perturbation and input torque variation successfully. It is found that:

$>$ The machine side converter control is managing the reference speed to extract the power from the input. As a result, dc link voltage remains constant throughout the operation. It is also observed that dc link voltage is having only $2 \%$ variation during transient condition for input torque and output load perturbation, and is settled within $0.8 \mathrm{sec}$.

$>$ The total power supplied by the generator side VSC increases due to the increment in the load demand, while the total power supplied by the machine side converter is kept at same level during the change in the input torque. The speed increases to accommodate the increased load power, while decreases with the increment in the input torque.

$>$ The control of load side VSC is successfully keeping the load voltage constant throughout the study. The transient variations during changes are settling to provide constant $d$-axis and q-axis components of load voltage.

The designed filter is capable of keeping the THD for load current less than $2 \%$.

The system is so capable of future extension towards grid-connected operation.

\section{References}

[1]. M. Kalantar and S. M. Mousavi G., "Dynamic behavior of a stand-alone hybrid power generation system of a wind turbine, microturbine, solar array and battery storage," Applied Energy, vol. 87, no. 10, pp. 3051 -3064, 2010.

[2]. C. N. Bhende, S. Mishra, and S. G. Malla, "Permanent Magnet Synchronous GeneratorBased Standalone Wind Energy Supply System," IEEE Transactions Sustainable Energy, vol. 2, no. 4, pp. 361-373, 2011.

[3]. R. Cardenas and R. Pena, "Sensorless vector control of induction machines for variablespeed wind energy applications," IEEE Transactions Energy Conversion, vol. 19, no. 1, pp. 196-205, 2004.

[4]. N. H. Malik and A. H. Al-Bahrani, "Influence of the terminal capacitor on the performance characteristics of a self-excited induction generator," IEE Proceedings $C$ Generation, Transmission and Distribution, vol. 137, no. 2, pp. 168-173, 1990.

[5]. J. Lee and Y. S. Kim, "Sensorless fuzzy-logic-based maximum power point tracking control for a small-scale wind power generation systems with a switched-mode rectifier," IET Renewable Power Generation, vol. 10, no. 2, pp. 194-202, 2016.

[6]. R. Teodorescu and F. Blaabjerg, "Flexible control of small wind turbines with grid failure detection operating in stand-alone and grid-connected mode," IEEE Transactions Power Electronics, vol. 19, no. 5, pp. 1323-1332, 2004.

[7]. R. Pena, J. C. Clare, and G. M. Asher, "Doubly fed induction generator using back-toback PWM converters and its application to variable-speed wind-energy generation," IEE Proceedings - Electric Power Applications, vol. 143, no. 3, pp. 231-241,1996.

[8]. G. Tapia, G. SantamarÍa, M. Telleria and A. Susperregui, "Methodology for Smooth Connection of Doubly Fed Induction Generators to the Grid," IEEE Transactions Energy Conversion, vol. 24, no. 4, pp. 959-971, 2009.

[9]. Manaullah, A. K. Sharma, H. Ahuja, and A. Singh, "Performance comparison of DFIG and SCIG based wind energy conversion systems," Computational Intelligence on Power, Energy and Controls with their impact on Humanity (CIPECH), 2014 Innovative Applications of, Ghaziabad, pp. 285-290,2014. 
[10].S. Hazra and P. Sensarma,"Vector approach for self-excitation and control of induction machine in stand-alone wind power generation," IET Renewable Power Generation, vol. 5, no. 5, pp. 397-405, 2011.

[11].W. Suebkinorn and B. Neammanee, "An implementation of field oriented controlled SCIG for a variable speed wind turbine," 2011 6th IEEE Conference on Industrial Electronics and Applications, Beijing, pp. 39-44,2011.

[12].M. A. H. Navas, J. L. A. Puma, and A. J. S. Filho, "Direct torque control for squirrel cage induction generator based on wind energy conversion system with the battery energy storage system," Power Electronics and Power Quality Applications (PEPQA), 2015, Bogota, pp. 1-6, 2015.

[13].J. Alcalá, E. Bárcenas, and V. Cárdenas, "Practical methods for tuning PI controllers in the -link voltage loop in Back-to-Back power converters," Power Electronics Congress (CIEP), San Luis Potosi, pp. 46-52, 2010.

[14].L. Yang, Z. Xu, J. Ostergaard, Z. Y. Dong and K. P. Wong, "Advanced Control Strategy of DFIG Wind Turbines for Power System Fault Ride Through," IEEE Transactions on Power Systems, vol. 27, no. 2, pp. 713-722, May 2012.

[15].M. J. Zandzadeh, A. Vahedi, and A. Zohoori, "A novel direct power control strategy for integrated DFIG/active filter system," 20th Iranian Conference on Electrical Engineering (ICEE2012), Tehran, 2012, pp. 564-568.

[16].S. Ghosh, S. Kamalasadan, "An Energy Function-Based Optimal Control Strategy for Output Stabilization of Integrated DFIG-Flywheel Energy Storage System," IEEE Transactions on Smart Grid, PP 1-10, no.99, pp.1-10 04 Feb. 2016.

[17].M. Patnaik and D. Kastha, "Control of Double Output Induction Machine Based standalone Variable Speed Constant Frequency generator with nonlinear and unbalanced loads," IEEE PES General Meeting, Minneapolis, MN, 2010, pp.1-8.

[18].M. Patnaik and D. Kastha, "Reactive power based MRAS observer for speed sensorless control of double output induction generator," 2010 5th International Conference on Industrial and Information Systems, Mangalore, 2010pp.556-561.

[19].P. Mungporn et al., "Dynamics improvement of the 3-phase inverter with output LC-filter by using differential flatness based control for grid connected applications," 2016 19th International Conference on Electrical Machines and Systems (ICEMS), Chiba, Japan, 2016, pp. 1-6.

[20].T. Thavaratnam, C. Li and D. Xu, "Switching frequency selection for aerospace power converter system considering the design of output LC filter inductor optimizing weight and power loss," 2016 IEEE Electrical Power and Energy Conference (EPEC), Ottawa, ON, 2016, pp. 1-5.

[21].X. Wei, L. Xiao, Z. Yao and C. Gong, "Design of LCL filter for wind power inverter," 2010 World Non-Grid-Connected Wind Power and Energy Conference, Nanjing, 2010, pp. 1-6. 


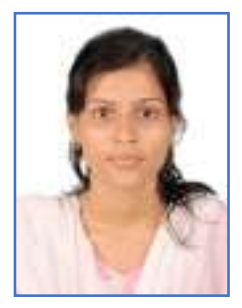

Rupa Mishra is currently working towards the Ph.D. degree in the Department of Electrical Engineering, National Institute of Technology, Durgapur, India. Her research interests are Machine drives, Power-electronic and its applications and renewable energy.

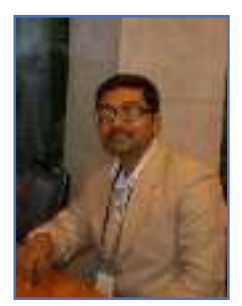

Tapas Kumar Saha received the received the B.E. degree in electrical engineering from the Jalpaiguri Government Engineering College, University of North Bengal, Jalpaiguri, India, in 1997, the M.E in Electrical Machines from the Jadavpur University, Kolkata, India, in 1999, and the Ph.D. degree from the Electrical Engineering Department, Indian Institute of Technology, Kharagpur, India, in 2009.He is currently an Associate Professor in the Department of Electrical Engineering, National Institute of Technology Durgapur, India. His current research interests are machine drives, power electronics, renewable energy and the grid integrated distributed generations. 